\title{
Genome-wide linkage and association scans for pulse pressure in Chinese twins
}

\begin{abstract}
Dongfeng Zhang ${ }^{1}$, Zengchang Pang ${ }^{1,2}$, Shuxia $\mathrm{Li}^{3}$, Wenjie Jiang ${ }^{1}$, Shaojie Wang ${ }^{2}$, Mads Thomassen ${ }^{3}$, Jacob v B Hjelmborg ${ }^{4}$, Torben A Kruse ${ }^{3}$, Kirsten Ohm Kyvik ${ }^{5}$, Kaare Christensen ${ }^{6}$, Gu Zhu ${ }^{7}$ and Qihua Tan $^{3,6}$

Elevated pulse pressure (PP) is associated with cardiovascular disorders and mortality in various populations. The genetic influence on PP has been confirmed by heritability estimates using related individuals. Recently, efforts have been made by mapping genes that are linked to the phenotype. We report the results of our gene mapping studies conducted in the Chinese population in mainland China. The genome-wide linkage and association scans were carried out on 63 middle-aged dizygotic twin pairs using high-density markers. The linkage analysis identified three significant linkage peaks (all with a single point $P<1 \mathrm{e}^{-05}$ ) on chromosome 11 (LOD core 4.06 at $30.5 \mathrm{cM}$ ), chromosome 12 (LOD score 3.97 at $100.7 \mathrm{cM}$ ) and chromosome 18 (LOD score 4.01 at $70.7 \mathrm{cM}$ ), with the last two peaks closely overlapping with linkage peaks reported by two American studies. Multiple regions with suggestive linkages were identified, with many of the peaks overlapping with published linkage regions. The genome-wide association analysis detected a suggestive association on chromosome 4 (rs 17031508 , $P<8.34 \mathrm{e}^{-08}$ ) located within a wide region of suggestive linkage. Our results provide some evidence for genetic linkages and associations with PP in the Chinese population. Further investigation is warranted to replicate the findings and to explore the susceptibility loci or genes for PP.

Hypertension Research (2012) 35, 1051-1057; doi:10.1038/hr.2012.90; published online 5 July 2012
\end{abstract}

Keywords: association analysis; Chinese twins; genome-wide; linkage analysis; pulse pressure

\section{INTRODUCTION}

Pulse pressure (PP) measures the change in blood pressure during a contraction of the heart. Elevated PP has been associated with cardiovascular disorders and mortality. ${ }^{1}$ Several anthropometric factors have been shown to affect PP. For example, aging results in increased stiffness and loss of elasticity in the aorta and major artery, leading to increased $\mathrm{PP}^{2}$ In addition, body size (and consequently, gender) affects PP by altering the magnitude and timing of wave reflection. ${ }^{3,4}$ Recently, the age and gender effects have been shown to be cross-cultural. ${ }^{5}$

In addition to anthropometric factors, genetic epidemiology studies using family and twin data have provided verifiable evidence for a low to modest genetic contribution to PP with heritability estimates ranging from 0.13 using twins in the United Kingdom, ${ }^{6} 0.21^{7}$ and $0.24^{8}$ in European pedigrees, to 0.35 and 0.54 in American Caucasian $^{9}$ and African ${ }^{10}$ families, respectively. An even higher heritability estimate of 0.63 was reported by a Swedish study. ${ }^{11}$ A recent analysis of our Chinese twin data showed a heritability estimate of 0.45 (unpublished data), which is consistent with the American and African data. These results indicate that, similar to all other complex traits, the etiology of PP can be complicated due to the involvement of both genetic and environmental dissections. ${ }^{12}$

The existence of a genetic contribution has warranted efforts to elucidate genes that affect PP, especially in recent years. For example, genetic marker-based linkage studies have identified multiple loci harboring susceptibility genes for PP in different populations, including Caucasians, ${ }^{9,13,14}$ Mexicans, ${ }^{15}$ American Indians ${ }^{16}$ and African Americans. ${ }^{17}$ The verification of susceptibility loci requires replication studies within and across populations to consolidate linkage results, which is especially important given the fact that inconsistent linkage results were reported by different studies. ${ }^{12}$

Twins are of special interest for genetic studies of complex diseases or phenotypes because, as naturally matched pairs, the confounding effects of a large number of potentially causal factors are matched when comparing twins who share them. In addition to heritability estimates, twins also serve as valuable samples for gene mapping advantaged by low confounding and low probability of non-paternity, which results in increased power. ${ }^{18}$ We report herein the results from the first extensive twin-based genetic epidemiology study on PP in the Chinese population, where hypertension has become the most

\footnotetext{
${ }^{1}$ Department of Public Health, Qingdao University Medical College, Qingdao, China; ${ }^{2}$ Qingdao Center for Disease Control and Prevention, Qingdao, China; ${ }^{3}$ Department of Clinical Genetics, Odense University Hospital, Odense, Denmark; ${ }^{4}$ Department of Biostatistics, Institute of Public Health, University of Southern Denmark, Odense, Denmark; ${ }^{5}$ Institute for Regional Health Research, University of Southern Denmark, Odense, Denmark; ${ }^{6}$ Epidemiology, Institute of Public Health, University of Southern Denmark, Odense, Denmark and ${ }^{7}$ Genetic Epidemiology Unit, Queensland Institute of Medical Research, Australia

Correspondence: Professor D Zhang, Department of Public Health, Qingdao University Medical College, Deng Zhou Street 38, Qingdao 266021, China.

E-mail: zhangdf1961@126.com
}

Received 21 November 2011; revised 17 April 2012; accepted 18 April 2012; published online 5 July 2012 
common risk factor for cardiovascular and cerebrovascular diseases, which are among the top three leading causes of death in China. Genome-wide gene mapping was conducted using high-density single-nucleotide polymorphism (SNP) markers, enabling both linkage and association analyses across the genome. The results from our study will be compared with those reported in the literature, and the significance of our findings will be discussed.

\section{METHODS}

\section{Twin samples}

All of the twins were taken from the most recent wave of twin sampling for heritability study on multiple phenotypes associated with metabolic syndrome conducted by the Qingdao Twin Registry ${ }^{19,20}$ at the Qingdao Center for Disease Control and Prevention in 2008 (Table 1). Twins were sampled through the local disease control network and residence registry. After receiving written consent, the twins were invited to a clinical investigation if both co-twins were alive. Those who were pregnant, breastfeeding, had known diabetes and/or cardiovascular disease, or were regularly taking any medications within 1 month before participation were excluded, and incomplete twin pairs were discharged. The zygosity of like-sex twin pairs was determined by DNA testing using 16 short tandem repeat DNA markers.

\section{Phenotypes}

Blood pressure was measured in a sitting position following standard procedure using a mercurial table stand model sphygmomanometer. Systolic blood pressure was calculated as Korotkoff phase I (appearance of sound), and diastolic blood pressure was calculated as Korotkoff phase V (disappearance of sound). Three repeated measurements were taken for each subject, with at least 1 min between each measurement. The mean of these three measurements for systolic or diastolic blood pressure was used for analyses. PP was taken as the difference between the systolic and diastolic blood pressures. Body mass index (BMI) was calculated by taking one subject's weight (in $\mathrm{kg}$ ) and dividing it by the subject's height (in meters) squared. All measurements greater than 3 standard deviations above or below the mean were assigned as missing values. In Table 1, we present the descriptive statistics for monozygotic (MZ) and dizygotic (DZ) twins and their phenotypes separately. The generalized estimating equation model $^{21}$ was used to adjust the effect of age, sex and BMI on PP, all of which showed high statistical significance. The adjusted PP (that is, the residuals) was used for calculating the intra-class correlation coefficient $^{22}$ and for the heritability estimation. In Table 1 , the intra-class correlation coefficient in $\mathrm{MZ}$ twins is over two times higher than that in the DZ twins, suggesting the existence of genetic effects. In fact, results from our twin modeling showed that the model with additive genetic (A) and unique environment (E) effects (that is, the AE model) was the best model with a heritability estimate of $45 \%$, meaning that nearly half of the variation in PP is determined by genetic factors. These data form the basis for subsequent gene mapping.

\section{DNA samples and genotyping}

From the 241 pairs of DZ twins, 63 pairs were randomly selected for gene mapping using both linkage and association analyses. Whole-blood samples were taken for extracting leukocytes for DNA purification and genotyping using standard procedures. We used the Affymetrix Genome-Wide Human SNP Array 6.0 featuring 900000 SNP markers enabling high-resolution genome-wide analyses. Detailed information about the array can be found at the manufacturer's website (www.affymetrix.com). Genotyping was performed by the Affymetrix service provider, Shanghai Biochip, in China using purified DNA samples. High-quality genotyping was performed with a SNP calling rate ranging from 93.4 to $99 \%$. Before data analysis, we introduced an error detection procedure (-error) implemented in the free linkage software package Merlin. ${ }^{20}$ The procedure finds genotypes that provide information about gene flow in a pedigree that contradicts information provided by the other pedigrees. The procedure considers all available data simultaneously such that accuracy for each pedigree can be improved. The procedure retrieves a list of unlikely genotypes, which are then removed from the data using the Merlin
Table 1 Descriptive, regression and correlation analyses of twin data

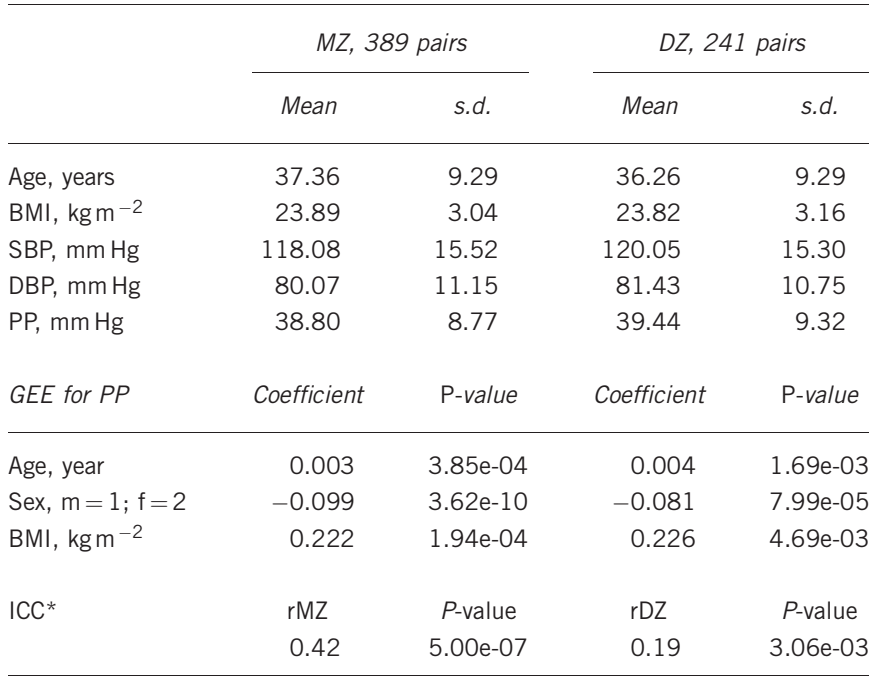

Abbreviations: BMI, body mass index; DBP, diastolic blood pressure; DZ, dizygotic; GEE, generalized estimating equation; ICC, intra-class correlation coefficient; PP, pulse pressure MZ, monozygotic; SBP, systolic blood pressure.

${ }^{*} \mathrm{ICC}$ in MZ and DZ twins are statistically significantly different with a $P$-value of $1.90 \mathrm{e}-03$ $(Z=3.10)$.

Table 2 Results of error detection by chromosome

\begin{tabular}{|c|c|c|c|c|}
\hline Chromosome & $\begin{array}{l}\text { Number } \\
\text { of SNPS }\end{array}$ & $\begin{array}{c}\text { Number } \\
\text { of valid SNPS }\end{array}$ & $\begin{array}{l}\text { Number of SNPS } \\
\text { with genotyping error }\end{array}$ & $\begin{array}{c}\text { Error } \\
\text { rate }^{*}(\%)\end{array}$ \\
\hline 1 & 73249 & 72301 & 948 & 1.29 \\
\hline 2 & 75893 & 75023 & 870 & 1.14 \\
\hline 3 & 62251 & 61474 & 777 & 1.25 \\
\hline 4 & 57532 & 56614 & 918 & 1.59 \\
\hline 5 & 57879 & 57249 & 630 & 1.09 \\
\hline 6 & 57838 & 57228 & 610 & 1.05 \\
\hline 7 & 48327 & 47815 & 512 & 1.06 \\
\hline 8 & 49839 & 49267 & 572 & 1.15 \\
\hline 9 & 42658 & 42288 & 370 & 0.87 \\
\hline 10 & 49510 & 49112 & 398 & 0.80 \\
\hline 11 & 45920 & 45520 & 400 & 0.87 \\
\hline 12 & 43787 & 43400 & 387 & 0.88 \\
\hline 13 & 35089 & 34677 & 412 & 1.17 \\
\hline 14 & 28882 & 28546 & 336 & 1.16 \\
\hline 15 & 26728 & 26516 & 212 & 0.79 \\
\hline 16 & 28636 & 28335 & 301 & 1.05 \\
\hline 17 & 21327 & 21117 & 210 & 0.98 \\
\hline 18 & 27170 & 26867 & 303 & 1.12 \\
\hline 19 & 12312 & 12190 & 122 & 0.99 \\
\hline 20 & 23480 & 23295 & 185 & 0.79 \\
\hline 21 & 12906 & 12764 & 142 & 1.10 \\
\hline 22 & 12003 & 11832 & 171 & 1.42 \\
\hline Total & 893216 & 883430 & 9786 & 1.10 \\
\hline
\end{tabular}

Abbreviation: SNP, single-nucleotide polymorphism.

*Percentage of SNPs excluded from analysis according to defined criterions.

command pedwipe. In Table 2, we show the information about error detection for each chromosome separately. As shown in the table, the SNP genotyping error rate for each chromosome is very low with a mean of only $1.1 \%$. The criteria for quality control and SNP filtering include a $P$-value for defining the Hardy-Weinberg equilibrium, which was set to $\geqslant 1 \mathrm{e}^{-04}$, the SNP call rate set to $\geqslant 95 \%$ and the sample call rate set to $\geqslant 95 \%$. 
Table 3 Significant and suggestive linkage peaks for pulse pressure

\begin{tabular}{|c|c|c|c|c|c|c|}
\hline Chromosome location & Closest marker & Reference SNP & LOD score & Point P-value & $\begin{array}{c}\text { Genome } \\
\text { significance }\end{array}$ & $\begin{array}{l}\text { Published } \\
\text { reference no. }\end{array}$ \\
\hline \multicolumn{7}{|l|}{ Chromosome 1} \\
\hline $90.6 \mathrm{~cm}$ & SNP_A-2061574 & rs11584915 & 3.05 & 9.0e-05 & No & \\
\hline $196.9 \mathrm{cM}$ & SNP_A-8711523 & rs12118925 & 3.54 & 3.0e-05 & No & 16 \\
\hline \multicolumn{7}{|l|}{ Chromosome 3} \\
\hline $32 \mathrm{cM}$ & SNP_A-2179383 & rs9869761 & 2.86 & $1.4 \mathrm{e}-04$ & No & 12 \\
\hline $93.9 \mathrm{cM}$ & SNP_A-8508966 & rs1387735 & 2.50 & 3.0e-04 & No & \\
\hline $152 \mathrm{cM}$ & SNP_A-2051216 & rs838610 & 3.60 & $2.0 e-05$ & No & \\
\hline \multicolumn{7}{|l|}{ Chromosome 4} \\
\hline $116 \mathrm{cM}$ & SNP_A-1916183 & rs2850413 & 3.08 & 8.0e-05 & No & \\
\hline \multicolumn{7}{|l|}{ Chromosome 5} \\
\hline $83.3 \mathrm{cM}$ & SNP_A-2158948 & rs33417 & 2.57 & 3.0e-04 & No & \\
\hline \multicolumn{7}{|l|}{ Chromosome 6} \\
\hline $78.3 \mathrm{cM}$ & SNP_A-8667531 & rs9357726 & 2.75 & $2.0 e-04$ & No & 12 \\
\hline $143.9 \mathrm{cM}$ & SNP_A-1941963 & rs9494756 & 3.19 & $6.0 e-05$ & No & \\
\hline \multicolumn{7}{|l|}{ Chromosome 7} \\
\hline $57.7 \mathrm{cM}$ & SNP_A-8399705 & rs6973458 & 3.24 & $6.0 \mathrm{e}-05$ & No & \\
\hline $74.4 \mathrm{cM}$ & SNP_A-4247483 & rs10270531 & 3.41 & 4.0e-05 & No & $13 ; 31$ \\
\hline $102.5 \mathrm{~cm}$ & SNP_A-8635038 & rs7781900 & 3.18 & 7.0e-05 & No & \\
\hline \multicolumn{7}{|l|}{ Chromosome 8} \\
\hline $26.5 \mathrm{~cm}$ & SNP_A-8293021 & rs17216024 & 2.79 & $2.0 \mathrm{e}-04$ & No & \\
\hline \multicolumn{7}{|l|}{ Chromosome 9} \\
\hline $159.5 \mathrm{cM}$ & SNP_A-8464500 & rs11103695 & 3.49 & 3.0e-05 & No & \\
\hline \multicolumn{7}{|l|}{ Chromosome 10} \\
\hline $134.5 \mathrm{~cm}$ & SNP_A-1832075 & rs7067647 & 2.80 & 2.0e-04 & No & \\
\hline \multicolumn{7}{|l|}{ Chromosome 11} \\
\hline $30.5 \mathrm{cM}$ & SNP_A-8636879 & rs11603765 & 4.06 & $1.0 \mathrm{e}-05$ & Yes & \\
\hline \multicolumn{7}{|l|}{ Chromosome 12} \\
\hline $100.7 \mathrm{~cm}$ & SNP_A-8445857 & rs2085866 & 3.97 & $1.0 \mathrm{e}-05$ & Yes & 12 \\
\hline \multicolumn{7}{|l|}{ Chromosome 15} \\
\hline $14.8 \mathrm{~cm}$ & SNP_A-8688089 & rs12592159 & 2.70 & $2.0 e-04$ & No & \\
\hline $115.6 \mathrm{cM}$ & SNP_A-8676706 & rs7177487 & 2.32 & $5.0 \mathrm{e}-04$ & No & 13 \\
\hline \multicolumn{7}{|l|}{ Chromosome 16} \\
\hline $3.1 \mathrm{~cm}$ & SNP_A-2181571 & rs4984954 & 2.87 & $1.4 \mathrm{e}-04$ & No & \\
\hline \multicolumn{7}{|l|}{ Chromosome 17} \\
\hline $75.3 \mathrm{cM}$ & SNP_A-1842000 & rs17645899 & 3.32 & 5.0e-05 & No & \\
\hline \multicolumn{7}{|l|}{ Chromosome 18} \\
\hline $70.7 \mathrm{cM}$ & SNP_A-2005638 & rs2576052 & 4.01 & $1.0 \mathrm{e}-05$ & Yes & 31 \\
\hline \multicolumn{7}{|l|}{ Chromosome 20} \\
\hline $86.1 \mathrm{cM}$ & SNP_A-2133602 & rs16997979 & 2.38 & $5.0 e-04$ & No & \\
\hline \multicolumn{7}{|l|}{ Chromosome 22} \\
\hline $5.6 \mathrm{cM}$ & SNP_A-1970673 & rs5746419 & 3.04 & 9.0e-05 & No & \\
\hline
\end{tabular}

Bold entries indicate linkages that reached genome-wide significance. 


\section{Genome-wide linkage analysis}

We applied the variance components method for non-parametric linkage analysis $^{23}$ to our genome-wide SNP marker data on the DZ twins. Data were analyzed with the linkage package Merlin. ${ }^{24}$ The variance components ${ }^{25}(-v c)$ procedure was used to test for linkage of $\mathrm{PP}$ with age, sex and BMI incorporated as covariates.

Although our high-density SNP map increases the linkage information content that is important in the non-parametric linkage analysis, ${ }^{26}$ it could also result in a linkage disequilibrium (LD) among adjacent SNPs. When parental phase information is missing, $\mathrm{LD}$ can lead to an overestimation of the number of alleles shared identical-by-descent and thus inflate the LOD score estimates. ${ }^{27}$ To accommodate LD, we adopted a SNP-dropping strategy similar to Cho and Dupuis ${ }^{27}$ by picking up SNPs for linkage analysis at approximately every $5 \mathrm{cM}$. According to their simulation study, this stringent strategy efficiently eliminates the LOD score inflation due to LD in the case of dense markers.

The genome-wide significance of the identified linkage peaks was assessed by applying the threshold criterion provided by Lander and Kruglyak ${ }^{28}$ with a score of 2.2 for suggestive linkages and 3.6 for genome-wide significant linkages.

\section{Genome-wide association analysis}

The high-density SNP markers enable us to perform a genome-wide association study (GWAS) on PP. To this end, the score test (-fastAssoc) for the family-based association analysis implemented in Merlin was used, with age, sex and BMI included as covariates. The family-based association test allows phenotype correlation among family members (in this case, the twin pair) by introducing a kinship coefficient in the variance component-based
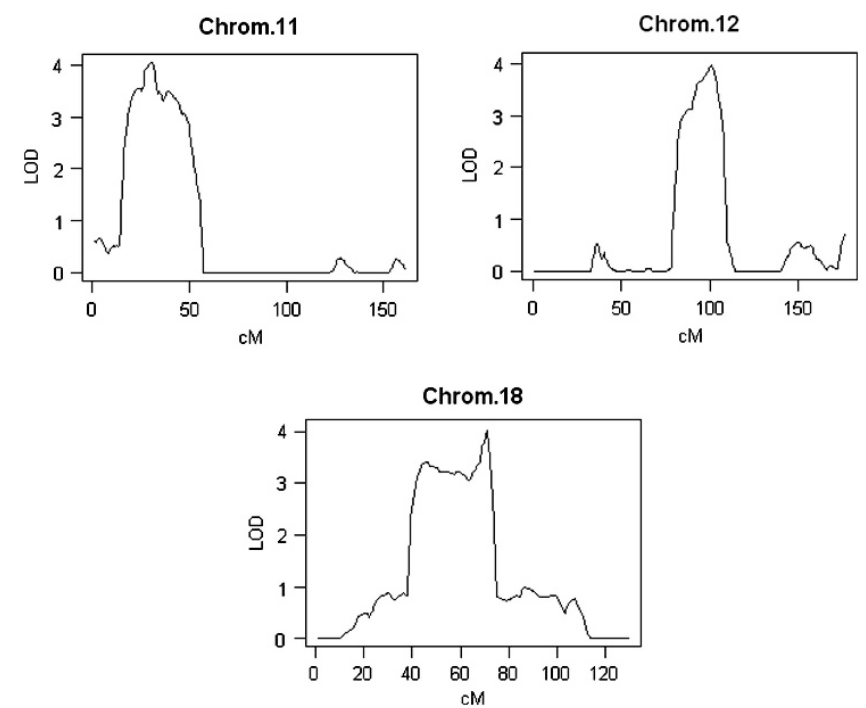

Figure 1 The significant linkage peaks identified on chromosomes 11,12 and 18 with LOD score estimates of $4.06,3.97$ and 4.01 , respectively. approach. ${ }^{29}$ Association analysis was performed assuming additive genetic effects and SNPs with minor allele frequency $<5 \%$ were dropped. The genome-wide significance level was set stringently to $P<5 \mathrm{e}^{-08}$.

\section{RESULTS}

\section{Genome-wide linkage analysis}

With age, sex and BMI incorporated as covariates, our whole-genome linkage scan (Table 3) identified three significant linkage peaks on chromosome 11 (LOD score of 4.06, linkage region from 26 to $33 \mathrm{cM}$ ), chromosome 12 (LOD score of 3.97, from 93 to $104 \mathrm{cM}$ ) and chromosome 18 (LOD score of 4.01, from 68 to $72 \mathrm{cM}$ ) (Figure 1, Table 3), together with multiple suggestive linkage peaks with LOD scores over 3 on chromosome 1 ( 3.05 from 81 to $100 \mathrm{cM}, 3.54$ from 170 to $242 \mathrm{cM}$ ), chromosome 3 (3.6 from 141 to $170 \mathrm{cM}$ ), chromosome 4 (3.08 from 72 to $128 \mathrm{cM}$ ), chromosome 6 (3.19 from 129 to $163 \mathrm{cM}$ ), chromosome 7 (3.24 from 55 to $64 \mathrm{cM}, 3.41$ from 68 to $88 \mathrm{cM}, 3.18$ from 95 to 116 ), chromosome 9 (3.49 from 154 to $167 \mathrm{cM})$, chromosome 17 (3.32 from 61 to $103 \mathrm{cM}$ ) and chromosome $22(3.04$ from 1 to $31 \mathrm{cM})$.

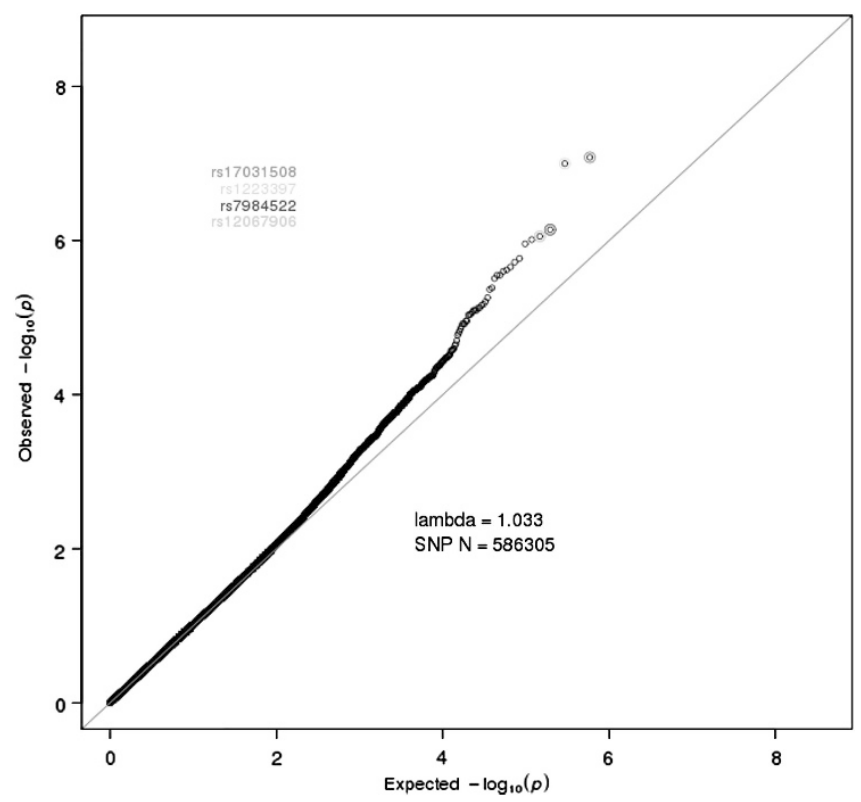

Figure 3 Quantile-quantile $(Q-Q)$ plot for data in Figure 3. Relative importance is shown for the top SNPs that deviate from the middle line between the $x$ axis and $y$ axis. A full color version of this figure is available at the Hypertension Research journal online.

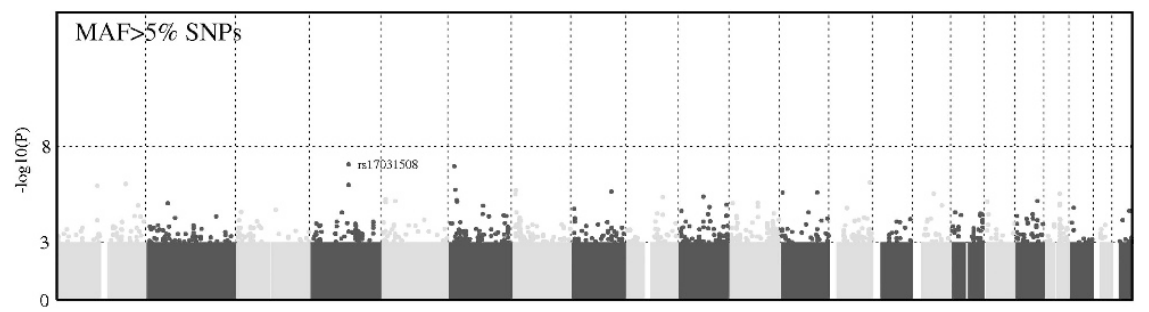

Figure 2 Manhattan plot for GWAS of pulse pressure. The strongest association is shown by SNP rs17031508 (102779313 bp) on chromosome 4. A full color version of this figure is available at the Hypertension Research journal online. 
Table 4 Detailed information for the top significant SNPs

\begin{tabular}{|c|c|c|c|c|c|c|c|c|c|c|}
\hline Chromosome & SNP & Base pair & Affymetrix ID & $c M$ & $\begin{array}{l}\text { Closest } \\
\text { genes }\end{array}$ & $\begin{array}{l}\text { Distance to } \\
\text { genes }(B P)\end{array}$ & P-value & $\begin{array}{l}\text { Effect- } \\
\text { allele }\end{array}$ & $\begin{array}{c}\text { Effect- } \\
\text { size }\end{array}$ & $\begin{array}{c}\text { Allele } \\
\text { frequency }\end{array}$ \\
\hline 1 & rs12067906 & 192431998 & SNP_A-2232678 & 198,2338 & $\begin{array}{l}\text { RGS21 } \\
\text { PPP3CA }\end{array}$ & $\begin{array}{c}95583 \\
291937\end{array}$ & $8,76 \mathrm{E}-07$ & 1 & 1.556 & 0.945 \\
\hline 4 & rs17031508 & 102779313 & SNP_A-8589212 & 112,3186 & $\begin{array}{l}\text { BANK1 } \\
\text { PPP3CA }\end{array}$ & $\begin{array}{l}151473 \\
300105\end{array}$ & $8,34 \mathrm{E}-08$ & 2 & 0.888 & 0.841 \\
\hline 4 & rs4580657 & 102787481 & SNP_A-8690649 & 112,3249 & BANK1 & 143305 & $9,74 \mathrm{E}-07$ & 1 & 1.034 & 0.881 \\
\hline 6 & rs1223397 & 13378924 & SNP_A-8537269 & 32,41495 & PHACTR1 & 0 & $1,04 \mathrm{E}-07$ & 1 & 1.706 & 0.911 \\
\hline 13 & rs7984522 & 108145660 & SNP_A-4249816 & 115,9055 & MY016 & 0 & $7,21 \mathrm{E}-07$ & 1 & 2.447 & 0.944 \\
\hline
\end{tabular}

Abbreviation: SNP, single-nucleotide polymorphism.

\section{Genome-wide association study}

Figure 2 is the Manhattan plot for our GWAS results. As a measure for genomic control, an inflation factor Lambda ${ }^{30}$ was estimated to be 1.033, suggesting sample homogeneity. The SNP showing the strongest association ( $\mathrm{rs} 17031508$ at $102779313 \mathrm{bp}, \sim 112.3 \mathrm{cM}$ ) resides in the middle of chromosome 4 with a $P$-value of $8.34 \mathrm{e}^{-08}$. Another SNP (rs1223397 at $13378924 \mathrm{bp}, \sim 32.41 \mathrm{cM})$ on chromosome 6 showed a $P$-value of $1.04 \mathrm{e}^{-07}$. The data in Figure 2 are also plotted in a quantile-quantile plot (Figure 3) such that the relative importance of SNPs can be easily perceived. With the stringent level for defining genome-wide significance $\left(P<5 \mathrm{e}^{-08}\right)$, no significant SNP was found in our GWAS, although SNP rs17031508 is close to significance. In Table 4, we listed the top five SNPs displaying high levels of association with detailed information concerning SNP IDs, reference number, chromosome location and frequency.

\section{DISCUSSION}

We have conducted the first extensive genetic epidemiology study on PP in the Chinese population using both linkage and association approaches. Our linkage and association analyses identified multiple genomic regions harboring susceptibility loci for PP, together with multiple SNPs, showing suggestive evidence of genome-wide association. Although each of the two approaches focused on different aspects of the genetic architecture of PP (that is, linkage mainly captures rare variants with large effects, while association detects common variations with small effects), overall, our results emphasize the genetic control over hemodynamic conditions.

Three linkage peaks that reside separately on chromosomes 11,12 and 18 have been found to show genome-wide significance (LOD score $>3.6$ ) with their LOD score estimates of $\sim 4$. It is surprising that among the three significant linkage peaks, two have been confirmed to show linkage in other populations. In a multipoint linkage scan performed on large and extended Utah pedigrees, Camp et al. $^{31}$ reported linkage evidence on chromosome $12 \mathrm{q}$ at $109 \mathrm{cM}$, which is covered by our linkage region on chromosome 12 in Figure 1. In another study based on American families, Bielinski et al. ${ }^{13}$ detected a significant linkage for PP on chromosome 18 at $71 \mathrm{cM}$; this was the most significant linkage in their study. It is interesting that this is exactly the location for our linkage peak on chromosome 18 (at $70.75 \mathrm{cM}$, Figure 1). Considering that there has been a limited number of whole-genome linkage scans conducted on $\mathrm{PP}$ in the literature, it is very unlikely that these results are coincidences.

Multiple suggestive linkages were detected by our linkage scan (Table 3). We assume that their trustworthiness increases with their

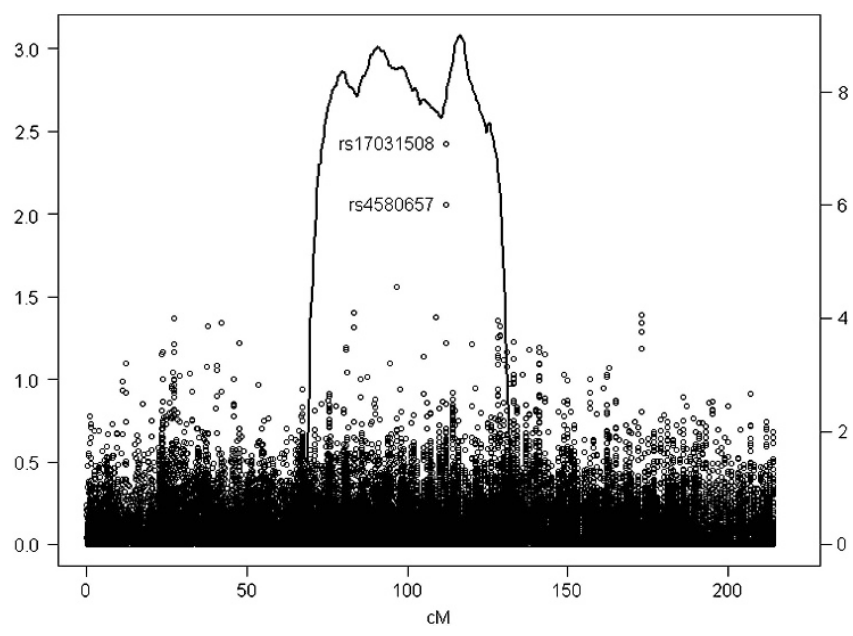

Figure 4 Linkage and association plots superimposed on chromosome 4. The two topmost SNPs detected by the association analysis reside in a broad region showing suggestive linkage in the middle of chromosome 4.

LOD score magnitudes, which seems to be reasonable considering the fact that four suggestive peaks with LOD scores $>3$ overlap with reported linkages in previous studies. The highest suggestive linkage peak on chromosome 1 lies in the same region where Sherva et al. ${ }^{17}$ reported a suggestive linkage at $215 \mathrm{cM}$. This region is where the $\mathrm{G}$ protein-coupled receptor gene resides, which is involved in the signaling cascades that regulate blood pressure during changes in cardiac output. ${ }^{17}$ The highest suggestive linkage peak on chromosome 7 at $74.37 \mathrm{cM}$ coincides with a linkage peak at $75 \mathrm{cM}$ reported by Bielinski et al. ${ }^{13}$ and is in the vicinity of a peak at $71 \mathrm{cM}$ in the same region reported by DeStefano et al. ${ }^{15}$ The peak regions on chromosomes 17 and 22 cover linkage peaks for PP reported by Bielinski et al. ${ }^{13}$ (at $89 \mathrm{cM}$ on chromosome 17 and $11 \mathrm{cM}$ on chromosome 22). In addition, their study also detected linkages on chromosomes $1(106 \mathrm{cM}), 3(172 \mathrm{cM})$ and $7(75 \mathrm{cM})$, which are located in the vicinity of our suggestive regions. All of these results emphasize the importance of our suggestive linkages.

The performances of SNP and traditional microsatellite markers in linkage analysis have been compared by Schaid et al..$^{32}$ and Evans and Cardon, ${ }^{33}$ who consistently reported a higher information content from the dense map of SNP markers than the from the microsatellite markers spaced at one marker per $\sim 10 \mathrm{cM}$. Moreover, it was reported that linkage mapping using dense SNP markers identified more linkage peaks with narrower widths than did the traditional 
markers. ${ }^{32}$ This conclusion coincides with our multiple suggestive scores, many of which overlap with linkage peaks detected by published large studies.

This study performed the first GWAS on PP in mainland Chinese. Although our sample size is relatively small, important associations have been identified. It is interesting to note that the SNP of the strongest association (rs17031508) is located within a wide region of suggestive linkage in the middle of chromosome 4 (Figure 4). Another nearby SNP (rs4580657, only 8168 bp away) also showed a strong association, although weaker than rs17031508. These results emphasize the importance of the corresponding region on chromosome 4. In fact, one of the closest genes to the two SNPs is the PPP3CA gene, which is known as the calcineurin gene. This gene has been reported to be associated with cardiac phenotypes, including stroke volume, cardiac output, and left ventricular hypertrophy in Chinese young adults. ${ }^{34}$ The second SNP of top rank association, rs1223397, resides in phosphatase and actin regulator 1 gene (PHACTR1) on chromosome 6. Recently, variations in this gene have been associated with early-onset myocardial infarction ${ }^{35}$ and with coronary heart disease. ${ }^{36}$ Considering our limited sample size, further replication studies in Chinese and other ethnic populations are needed to reconfirm our identified associations and to explore the genetic correlation between PP and the risk of cardiac disorders. Finally, we note that the quantile-quantile plot in Figure 3 departs relatively early from the line of identity, which could mean a systematic effect due to the population substructure in our sib-pair data that is not completely accounted for in our analysis. Despite this, the large deviations from the reference line by the top SNPs show clear evidence of association.

Zhao et al. ${ }^{37}$ reported significant effects of dietary factors, including salt intake, on blood pressure differences between Chinese in the north (higher salt intake) and in the south (lower salt intake). As a limitation of the study, salt intake was not measured and thus cannot be adjusted; however, individual adjustment on a population factor can only have a limited effect within the same population. In contrast, our models for gene mapping that are based on twin pairs could help to match the effects of shared environmental factors (for example, family dietary habits). After all, it is encouraging to note that our results based on Chinese data are consistent with those from studies on other ethnic populations, which provides new support to the conclusion that the effects of these factors are cross-cultural. ${ }^{5}$

Linkages and associations identified by us, especially those overlapping closely with previous studies, encourage further investigations with the aim of identifying genetic variations that affect PP using more focused linkage and association approaches on large samples. Meanwhile, considering the limited sample size used in the study, the interpretation of our findings, especially the multiple suggestive linkages and associations of borderline significance (for example, rs17031508), should be performed with caution because the validity of these loci requires additional replication studies to be conducted, particularly in Chinese and Asian populations.

\section{CONFLICT OF INTEREST}

The authors declare no conflict of interest.

\section{ACKNOWLEDGEMENTS}

This project was funded by the European Foundation for the Study of Diabetes, the 2007 Research Project: A genome-wide linkage analysis on metabolic/intermediate phenotypes predisposing to type II diabetes in the Chinese population and by the National Natural Science Foundation of China (grant no. 30872170).
1 Dart AM, Kingwell BA. Pulse pressure-a review of mechanisms and clinical relevance. J Am Coll Cardiol 2001; 37: 975-984.

2 Franklin SS, Gustin W, Wong ND, Larson MG, Weber MA, Kannel WB, Levy D. Hemodynamic patterns of age-related changes in blood pressure: the Framingham heart study. Circulation 1997; 96: 308-315.

3 London GM, Guerin AP, Pannier B, Marchais SJ, Stimpel M. Influence of sex on arterial hemodynamics and blood pressure: role of body height. Hypertension 1995; 26 514-519.

4 Smulyan H, Marchais SJ, Pannier B, Guerin AP, Safar ME, London GM. Influence of body height on pulsatile arterial hemodynamic data. J Am Coll Cardiol 1998; 31: 1103-1109.

5 Skurnick JH, Aladjem M, Aviv A. Sex differences in pulse pressure trends with age are cross-cultural. Hypertension 2010; 55: 40-47.

6 Snieder H, Hayward CS, Perks U, Kelly RP, Kelly PJ, Spector TD. Heritability of central systolic pressure augmentation: a twin study. Hypertension 2000; 35 574-579.

7 Pilia G, Chen WM, Scuteri A, Orrú M, Albai G, Dei M, Lai S, Usala G, Lai M, Loi P, Mameli C, Vacca L, Deiana M, Olla N, Masala M, Cao A, Najjar SS, Terracciano A, Nedorezov T, Sharov A, Zonderman AB, Abecasis GR, Costa P, Lakatta E, Schlessinger D. Heritability of cardiovascular and personality traits in 6,148 Sardinians. PLoS Genet. 2006; 2: e132

8 van Rijn MJ, Schut AF, Aulchenko YS, Deinum J, Sayed-Tabatabaei FA, Yazdanpanah M, Isaacs A, Axenovich TI, Zorkoltseva IV, Zillikens MC, Pols HA, Witteman JC, Oostra $\mathrm{BA}$, van Duijn CM. Heritability of blood pressure traits and the genetic contribution to blood pressure variance explained by four blood-pressure-related genes. $J$ Hypertens 2007; 25: 565-570.

9 Mitchell GF, DeStefano AL, Larson MG, Benjamin EJ, Chen MH, Vasan RS, Vita JA, Levy D. Heritability and a genome-wide linkage scan for arterial stiffness, wave reflection, and mean arterial pressure: the Framingham Heart Study. Circulation 2005, 112: 194-199.

10 Bochud M, Bovet P, Elston RC, Paccaud F, Falconnet C, Maillard M, Shamlaye C, Burnier M. High heritability of ambulatory blood pressure in families of East African descent. Hypertension 2005; 45: 445-450.

11 Fava C, Burri P, Almgren P, Groop L, Hulthén UL, Melander O. Heritability of ambulatory and office blood pressure phenotypes in Swedish families. J Hypertens 2004; 22: 1717-1721.

12 Turner ST, Boerwinkle E. Genetics of blood pressure, hypertensive complications, and antihypertensive drug responses. Pharmacogenomics 2003; 4: 53-65.

13 Bielinski SJ, Lynch AI, Miller MB, Weder A, Cooper R, Oberman A, Chen YD, Turner ST, Fornage $M$, Province $M$, Arnett DK. Genome-wide linkage analysis for loci affecting pulse pressure: the Family Blood Pressure Program. Hypertension 2005; 46: $1286-1293$.

14 DeStefano AL, Larson MG, Mitchell GF, Benjamin EJ, Vasan RS, Li J, Corey D, Levy D. Genome-wide scan for pulse pressure in the National Heart, Lung and Blood Institute's Framingham Heart Study. Hypertension 2004; 44: 152-155.

15 Atwood LD, Samollow PB, Hixson JE, Stern MP, MacCluer JW. Genome-wide linkage analysis of blood pressure in Mexican Americans. Genet Epidemiol 2001; 20: 373-382.

16 Franceschini N, MacCluer JW, Rose KM, Rutherford S, Cole SA, Laston S, Göring HH, Diego VP, Roman MJ, Lee ET, Best LG, Howard BV, Fabsitz RR, North KE. Genomewide linkage analysis of pulse pressure in American Indians: the Strong Heart Study. Am J Hypertens 2008; 21: 194-199.

17 Sherva R, Miller MB, Lynch AI, Devereux RB, Rao DC, Oberman A, Hopkins PN, Kitzman DW, Atwood LD, Arnett DK. A whole genome scan for pulse pressure/stroke volume ratio in African Americans: the HyperGEN study. Am J Hypertens 2007; 20: 398-402.

18 Tan Q, Kyvik KO, Kruse TA, Christensen K. Dissection complex phenotypes using the genomics of twins. Funct Integr Genomics 2010; 10: 321-327.

19 Pang ZC, Ning F, Unger J, Johnson CA, Wang S, Guo Q, Cao WH, Lee LM. The Qingdao Twin Registry: a focus on chronic disease research. Twin Res Hum Genet 2006; 9: 758-762.

20 Duan H, Pang Z, Zhang D, Li S, Kruse TA, Kyvik KO, Christensen K, Tan Q. Genetic and environmental dissections of sub-phenotypes of metabolic syndrome in the Chinese population: A twin-based heritability study. Obesity Facts 2011; 4: 99-104.

21 Liang KY, Zeger SL. Longitudinal data analysis using generalized linear models. Biometrika 1986; 73: 13-22.

22 McGraw KO, Wong SP. Forming inferences about some intraclass correlation coefficients. Psychol Methods 1996; 1: 30-46.

23 Marlow AJ. Nonparametric linkage analysis. II. Variance components. Methods $\mathrm{Mol}$ Biol. 2002; 195: 61-100.

24 Abecasis GR, Cherny SS, Cookson WO, Cardon LR. Merlin-rapid analysis of dense genetic maps using sparse gene flow trees. Nat Genet 2002; 30: 97-101.

$25 \mathrm{Amos} \mathrm{Cl}$. Robust variance-components approach for assessing genetic linkage in pedigrees. Am J Hum Genet 1994; 54: 535-543.

26 Evans DM, Cardon LR. Guidelines for genotyping in genomewide linkage studies: single-nucleotide-polymorphism maps versus microsatellite maps. Am J Hum Genet 2004; 75: 687-692.

27 Cho K, Dupuis J. Handling linkage disequilibrium in qualitative trait linkage analysis using dense SNPs: a two-step strategy. BMC Genet 2009; 10: 44.

28 Lander E, Kruglyak L. Genetic dissection of complex traits: guidelines for interpreting and reporting linkage results. Nat Genet 1995; 11: 241-247. 
29 Chen WM, Abecasis GR. Family-based association tests for genomewide association scans. Am J Hum Genet 2007; 81: 913-926.

30 Devlin B, Roeder K. Genomic control for association studies. Biometrics 1999; 55 : 997-1004.

31 Camp NJ, Hopkins PN, Hasstedt SJ, Coon H, Malhotra A, Cawthon RM, Hunt SC. Genome-wide multipoint parametric linkage analysis of pulse pressure in large, extended utah pedigrees. Hypertension 2003; 42: 322-328.

32 Schaid DJ, Guenther JC, Christensen GB, Hebbring S, Rosenow C, Hilker CA, McDonnell SK, Cunningham JM, Slager SL, Blute ML, Thibodeau SN. Comparison of microsatellites versus single-nucleotide polymorphisms in a genome linkage screen for prostate cancer-susceptibility Loci. Am J Hum Genet 2004; 75: 948-965.

33 Evans DM, Cardon LR. Guidelines for genotyping in genomewide linkage studies: single-nucleotide-polymorphism maps versus microsatellite maps. Am J Hum Genet 2004; 75: 687-692.
34 He Z, Hu Y, Li Y, Bao D, Ruiz JR, Lucia A. Polymorphisms in the calcineurin genes are associated with the training responsiveness of cardiac phenotypes in Chinese young adults. Eur J Appl Physiol 2010; 110: 761-767.

35 Myocardial infarction genetics consortium. Genome-wide association of early-onset myocardial infarction with single nucleotide polymorphisms and copy number variants. Nat Genet 2009; 41: 334-340.

36 Ripatti S, Tikkanen E, Orho-Melander M, Havulinna A, Silander K, Sharma A, Guiducci C, Perola M, Jula A, Sinisalo J, Lokki M, Nieminen MS, Melander O, Salomaa V, Peltonen L, Kathiresan S. A multilocus genetic risk score for coronary heart disease: case-control and prospective cohort analyses. Lancet 2010; 376: 1393-1400.

37 Zhao L, Stamler J, Yan LL, Zhou B, Wu Y, Liu K, Daviglus ML, Dennis BH, Elliott P, Ueshima H, Yang J, Zhu L, Guo D. Blood pressure differences between northern and southern Chinese: role of dietary factors. Hypertension 2004; 43: 1332-1337. 